\title{
Habitual Snoring in school-aged children: environmental and biological predictors
}

\author{
Shenghui Li ${ }^{1,2}$, Xinming $\mathrm{Jin}^{3}$, Chonghuai Yan ${ }^{4}$, Shenghu Wu${ }^{4}$, Fan Jiang ${ }^{3}$, Xiaoming Shen ${ }^{4^{*}}$
}

\begin{abstract}
Background: Habitual snoring, a prominent symptom of sleep-disordered breathing, is an important indicator for a number of health problems in children. Compared to adults, large epidemiological studies on childhood habitual snoring and associated predisposing factors are extremely scarce. The present study aimed to assess the prevalence and associated factors of habitual snoring among Chinese school-aged children.

Methods: A random sample of 20,152 children aged 5.08 to 11.99 years old participated in a cross-sectional survey, which was conducted in eight cities of China. Parent-administrated questionnaires were used to collect information on children's snoring frequency and the possible correlates.
\end{abstract}

Results: The prevalence of habitual snoring was $12.0 \%$ (14.5\% for boys vs. 9.5\% for girls) in our sampled children. Following factors were associated with an increased risk for habitual snoring: lower family income (adjusted odds ratio $[\mathrm{OR}]=1.46)$, lower father's education $(\mathrm{OR}=1.38$ and 1.14 for middle school or under and high school of educational level, respectively), breastfeeding duration $<6$ months $(\mathrm{OR}=1.17)$, pregnancy maternal smoking $(\mathrm{OR}=$ 1.51), obesity $(\mathrm{OR}=1.50)$, overweight $(\mathrm{OR}=1.35)$, several respiratory problems associated with atopy and infection, such as chronic/allergic rhinitis $(O R=1.94)$, asthma $(O R=1.43)$, adenotonsillar hypertrophy $(O R=2.17)$, and chronic otitis media $(O R=1.31)$, and family history of habitual snoring $(O R=1.70)$.

Conclusion: The prevalence of habitual snoring in Chinese children was similar to that observed in other countries. The potential predisposing factors covered socioeconomic characteristics, environmental exposures, chronic health problems, and family susceptibility. Compared to socioeconomic status and family susceptibility, environmental exposures and chronic health problems had greater impact, indicating childhood habitual snoring could be partly prevented by health promotion and environmental intervention.

\section{Introduction}

Habitual snoring (HS), a prominent symptom of sleepdisordered breathing (SDB), usually defined as the presence of loud snoring at least three nights per week, is prevalent in children [1-8]. It was reported that the prevalence of $\mathrm{HS}$ in school-aged children was ranged from $4.9 \%$ to $17.1 \%$ in Western countries, such as Italy, Brazil, Germany, Portugal, Australia, and the USA [1-8]. There is a general recognition that HS is an important indicator for a number of health problems in children, including poor physical growth, emotional and behavioral problems, neurocognitive impairment and decreased

\footnotetext{
* Correspondence: shenxm9907@126.com

4Shanghai Key Laboratory of Children's Environmental Health, Shanghai, People's Republic of China

Full list of author information is available at the end of the article
}

academic performance, and less often cardiovascular abnormalities [8-13].

While the evidence for the existence of HS faced by many children and an association between HS and its negative consequences is becoming quite impressive, increasing attention should be focused on potential risk factors associated with childhood HS. However, it should be noted that studies, especially large epidemiological studies, on childhood HS and associated risk factors were scare. A few number of studies suggested that the influential factors regarding HS among children were multidimensional, including adenotonsillar hypertrophy, obesity, dental malocclusion, exposure to respiratory infections, cigarette smoking, recurrent otitis media, allergic rhinitis, and lower socioeconomic status [14-18].

\section{Biomed Central}


It was suggested that HS was physiologically partly determined by craniofacial structures [18]. There was evidence that craniofacial features were marked with racial differences [19]. Therefore, the prevalence and potential predisposing factors regarding HS may vary between different racial groups. Meanwhile, most studies regarding HS focused on children in European-American countries, with much less work being directed at children in Asian countries.

Studies in Thai and Hong Kong districts found that the prevalence of HS in school-aged children was $6.9 \%$ and 10.9 , respectively $[20,21]$. Due to a relatively small sample and restricted setting, the data from Thai and Hong Kong districts shouldn't be representative of Chinese children. Therefore, the present epidemiological study was designed to investigate the prevalence of HS and examine the predisposing factors on most of the currently known possible risk factors among a large nationally representative sample of school-aged children in Mainland, China.

\section{Methods and Materials}

\section{Study design and subjects}

Based on a cross-sectional design, 55 elementary schools from eight cities were selected during November and December of 2005, using a cluster-stratified selection procedure. These cities were Urumqi, Chengdu, Xi'an, Hohhot, Wuhan, Canton, Shanghai, and Harbin. For every city, 3-10 districts were randomly selected and within each district, 1-3 elementary schools were chosen. Among these districts and schools, 30 districts and 42 schools were located in urban areas and 9 districts and 13 schools were located in rural/suburban areas. The purposes of this research project were explained to school principals and teachers of the target schools. After the permissions were obtained from these schools, students who were eligible to participate in this study were invited to take the questionnaires on sleep behaviors and personal and family information to their parents, with a cover letter explaining the objectives of the project and instructions on how to complete the questionnaires. Parents were told that the participation was voluntary and informed consent was signed. Of 23,791 children recruited from six grades of the chosen schools, 22,018 (92.5\%) returned completed questionnaires.

It was well known that the pubertal development is accompanied by profound changes in biological characteristics, such as craniofacial and larynx structure, which were associated with SDB $[22,23]$. To eliminate the possible pubertal influences on the results of our study, children who had entered pubertal development were considered to be excluded. To the best of our knowledge, the definition of adolescence was varied between different countries. In China, adolescents usually refer to children aged $12 / 13$ to $17 / 18$ years old $[24,25]$. Therefore, 1313 children $\geq 12.00$ years of age were excluded from the sample. In addition, 536 children were also excluded because of being receiving medication with likely effects on sleep, such as psychostimulants, anticonvulsants, or antihistamines. Finally, 17 (0.1\%) children with missing information on frequency of snoring were excluded from further analyses. The final sample consisted of 20,152 children (49.3\% boys vs. $50.7 \%$ girls). The mean age of the sample was 9.01 years $(\mathrm{SD}=1.60$ years, range from 5.08 to 11.99 years).

The ethical application of this study was approved by the Ministry of Education of the People's Republic of China.

\section{Measure}

\section{Habitual snoring}

Sleep behaviors were assessed by a parents-administrated questionnaire - the Children's Sleep Habits Questionnaire (CSHQ). CSHQ is a 36-item instrument which was designed and developed to assess sleep behaviors of pre-school and school-aged children [26]. In short, the 33 CSHQ items were conceptually grouped into 8 subscales.

A Chinese version of the CSHQ was developed by translation and back translation and has been used previously with proven excellent sensitivity and reliability (Cronbach's alpha's for the internal consistency were 0.73 for the overall questionnaire and ranged from 0.420.69 for subscales; Intraclass correlation coefficients for the test-retest reliability were 0.85 for the overall questionnaire and ranged from $0.60-0.88$ for subscales; Intraclass correlation coefficients for the parallel reliability were 0.89 for the overall questionnaire and ranged from 0.83-0.92 for subscales) [26].

Subscale of SDB included three items regarding signs and symptoms related to SDB. The internal consistency (Cronbach's alpha) and test-retest reliability (ICCs) of the SDB subscale were 0.68 and 0.76 , respectively [27].

Snoring habit was investigated with the question: "How often does your child snore loudly during a typical recent week?" According to the CSHQ, the question was rated on a 3-point scale: "almost always" if occurred 5 to 7 nights per week; "frequently" for 2 to 4 nights per week; and "occasionally/never" for 0 to 1 night per week. For the purpose of this study, children were classified as habitual snorers if the answers were "almost always" or "frequently" and as nonhabitual snorers if the answers were "occasionally/never".

\section{Possible risk factors regarding HS}

In addition to age and gender, the possible risk factors were conceptually grouped into four domains: socioeconomic status (SES), environmental exposures, chronic health problems, and family member history of SDB. 
Socioeconomic variables included parents' educational levels (middle school or under [low], high school [medium], college or above [high]), and household income (< 800, 800-2500, and $\geq 2500$ RMB[yuan]/person/month).

Environmental exposure variables included delivery mode (caesarean section/vaginal birth), feeding patterns during the first four months after birth (breastfeeding, mixed feeding, and bottle feeding), duration of breastfeeding $(</ \geq 6$ months), pregnancy maternal smoking (yes/no), and household passive smoking (yes/no).

Children's chronic health problem variables included overweight/obesity status (yes/no, overweight and obesity were defined as body mass index [BMI] [weight in $\mathrm{kg} /$ height in $\left.\mathrm{m}^{2}\right] \geq 85^{\text {th }}$ and $\geq 95^{\text {th }}$ percentile, respectively), chronic respiratory condition (yes/no, with definition of being ever diagnosed with chronic/allergic rhinitis, asthma, otitis media, or adenotonsillar hypertrophy by pediatricians), and chronic food or drug allergy (yes/no).

Family history of SDB was investigated using the question: "Do the family members (including parents, grandparents, and siblings) habitually snore (yes/no) or were ever diagnosed with OSAS (yes/no)?"

\section{Statistical Analysis}

Statistical descriptions were made by use of the mean, standard deviation for continuous variables, and percentage for categorical variables. Independent-sample $t$ test and Chi-square test were used to compare differences between groups where appropriate (Table 1).

To identify risk factors regarding HS in our sampled children, the logistic regression analyses were performed, with " 1 " for HS and "0" for non-HS. Unadjusted odds ratios (OR) and 95\% confidence intervals (CI) for HS were calculated using univariate logistic regression (Table 2). Adjustments were further made by the multivariate regression models following a three-step procedure. Each model included additional variables to assess increasingly proximate determinants of HS. Firstly, a simple model (model I) adjusted only for age and gender (Tables 3 and 4). Secondly, variables regarding socioeconomic characteristics and environmental exposures (Table 3) or health problems and family history (Table 4) were further included (model II). Finally, a full model (model III) was established by adjusting age, gender, all socioeconomic and environmental factors, and all variables regarding health problems and family history simultaneously. The multivariate model included variables retaining significance after a forward likelihood-ratio stepwise elimination procedure. Statistical tests of regression estimates or odds ratio were based on Wald statistics.

All analyses were performed using the Statistical Package for Social Sciences (SPSS) for Windows, version
12.5 (SPSS Inc, Chicago, IL, USA). In the presentation of the results, the statistical significance was set at $\mathrm{P}$ value $<.05$ (two tailed).

\section{Results}

Prevalence of HS and characteristics of the sample

Our survey showed that the prevalence of HS in our sampled children was $12.0 \%$. Significantly gender difference was found with boys higher prevalent (14.5\% vs. 9.5\%; $\left.\chi^{2}=121.33, \mathrm{p}<.001\right)$. An interesting age differences were also found: first significantly increased from 5-6 to 7 years and then gradually declined $\left(\chi^{2}=18.09, \mathrm{p}=.004\right)$. Figure 1 showed the prevalence of HS by age.

Table 1 summarized the sample characteristics stratified by habitual snorers vs. nonhabitual snorers. Compared with nonhabitual snorers, habitual snorers were significantly younger, had higher BMI, and lower family income (all $\mathrm{p}<.001$ ). In addition, all chronic health problems, caesarean section, mixed/bottle feeding during the first four months after birth, breastfeeding $<6$ months, cigarette smoking exposure, and family history of SDB were more common in habitual snorers (all $\mathrm{p}<.001$ ).

\section{Predisposing factors of HS by logistical analyses}

The unadjusted OR with $95 \%$ CI of possible risk factors for HS were demonstrated in Table 2. It can be seen that, except for parental educational levels, all other factors were significantly associated with HS in the univariate regression models.

Socioeconomic characteristics and environmental exposures The association between HS and socioeconomic and environmental factors was shown in Table 3. After adjusting only for age and gender, those factors, such as lower family income, caesarean section, mixed/bottle feeding during the first four months after birth, breastfeeding $<6$ months, pregnancy maternal smoking, and household passive smoking were significantly associated with an increased likelihood of HS (Model I). After adjusting for socioeconomic factors and environmental exposures simultaneously, these six factors remained statistically significant (Model II). Moreover, father's educational level, which was not a significant predictor in Model I, was found to be related to HS in Model II. After adjusting further for all health problem and family history, four factors remained to be independent predictors of HS: lower family income, lower father's educational level, breastfeeding $<6$ months, and pregnancy maternal smoking (Model III).

The association between pregnancy maternal smoking and HS was stronger in girls than in boys $(\mathrm{OR}=2.46$ for girls, $\mathrm{OR}=1.16$ for boys; $\mathrm{p}$ for interaction $=.005$ ) .

\section{Health problems and family history}

The association between HS and health problems and family history was shown in Table 4. After adjusting 
Table 1 The characteristics for the study sample, Habitual Snorers vs. Nonhabitual Snorers $(n=20,152)$

\begin{tabular}{|c|c|c|c|c|c|}
\hline $\begin{array}{l}\text { Characteristics } \\
\mathrm{N}(\%) \\
\end{array}$ & $\begin{array}{c}\text { Total } \\
(\mathrm{N}=\mathbf{2 0 1 5 2 )} \\
\end{array}$ & $\begin{array}{l}\text { Habitual Snorers } \\
(\mathrm{N}=2418)\end{array}$ & $\begin{array}{l}\text { Nonhabitual Snorers } \\
(\mathrm{N}=17734)\end{array}$ & $t / \chi^{2}$ & $P$ value \\
\hline \multicolumn{6}{|l|}{ Sociodemographic characteristics } \\
\hline Age (years, mean \pm SD) & $9.00 \pm 1.60$ & $8.88 \pm 1.58$ & $9.02 \pm 1.61$ & $4.07^{\mathrm{a}}$ & $<.001$ \\
\hline Gender (\%) & & & & $121.33^{\mathrm{b}}$ & \\
\hline Boys & $9890(49.3)$ & $1437(59.9)$ & $8445(47.9)$ & & \\
\hline Girls & $10159(50.7)$ & $963(40.1)$ & $9188(52.1)$ & & \\
\hline $\mathrm{BMI}\left(\mathrm{Kg} / \mathrm{m}^{2}\right.$, mean $\left.\pm \mathrm{SD}\right)$ & $17.33 \pm 4.07$ & $17.85 \pm 4.40$ & $17.26 \pm 4.02$ & $6.18^{\mathrm{a}}$ & $<.001$ \\
\hline Family income (\%) & & & & $23.99^{\mathrm{b}}$ & $<.001$ \\
\hline$<800$ & $4853(24.4)$ & $671(28.2)$ & $4181(23.9)$ & & \\
\hline $800-2500$ & $11266(56.6)$ & $1309(55.0)$ & $9948(56.8)$ & & \\
\hline$\geq 2500$ & $3793(19.0)$ & $401(16.8)$ & $3385(19.3)$ & & \\
\hline Mather's education level (\%) & & & & $1.79^{\mathrm{b}}$ & .409 \\
\hline Low & $7653(38.7)$ & $644(27.4)$ & $4873(28.0)$ & & \\
\hline Medium & $6616(33.4)$ & $770(32.7)$ & $5843(33.5)$ & & \\
\hline High & $5527(27.9)$ & $940(39.9)$ & $6709(38.5)$ & & \\
\hline Father's education level (\%) & & & & $1.20^{\mathrm{b}}$ & .548 \\
\hline Low & $8433(42.1)$ & $587(24.5)$ & $4156(23.6)$ & & \\
\hline Medium & $6859(34.2)$ & $802(33.5)$ & $6050(34.3)$ & & \\
\hline High & $4750(23.7)$ & $1008(42.1)$ & $7422(42.1)$ & & \\
\hline \multicolumn{6}{|l|}{ Environmental exposures } \\
\hline Delivery & & & & $25.24^{\mathrm{b}}$ & $<.001$ \\
\hline Vaginal Birth & $13413(66.8)$ & $1497(62.3)$ & $11904(67.4)$ & & \\
\hline Caesarean section & $6658(33.2)$ & $906(37.7)$ & $5747(32.8)$ & & \\
\hline Feeding patterns during the first four months & & & & 11.43 & $<.001$ \\
\hline Breasting feeding & $13248(65.9)$ & $1512(62.8)$ & $11725(66.3)$ & & \\
\hline Mixed/bottle feeding & $6869(34.1)$ & $896(37.2)$ & $5967(33.7)$ & & \\
\hline Breast feeding & & & & $13.61^{b}$ & $<.001$ \\
\hline$\geq 6$ months & $10984(54.5)$ & $1230(51.0)$ & $9745(55.0)$ & & \\
\hline$<6$ months & $9168(45.5)$ & $1182(49.0)$ & $7978(45.0)$ & & \\
\hline Pregnancy maternal smoking & $389(1.9)$ & $76(3.2)$ & $313(1.8)$ & $21.42^{\mathrm{b}}$ & $<.001$ \\
\hline Household passive smoking & $5000(24.9)$ & $668(27.8)$ & $4332(24.5)$ & $12.43^{b}$ & $<.001$ \\
\hline \multicolumn{6}{|l|}{ Chronic health problems } \\
\hline Obesity & $2156(10.7)$ & $350(14.6)$ & $1806(10.2)$ & $37.55^{b}$ & $<.001$ \\
\hline Overweight & $2075(10.3)$ & $326(13.5)$ & $1749(9.8)$ & $24.18^{\mathrm{b}}$ & $<.001$ \\
\hline Chronic or allergic rhinitis & $1883(9.4)$ & $421(17.5)$ & $1460(8.2)$ & $212.54^{\mathrm{b}}$ & $<.001$ \\
\hline Asthma & $636(3.2)$ & $138(5.7)$ & $497(2.8)$ & $59.08^{b}$ & $<.001$ \\
\hline Adenotonsillar hypertrophy & $2218(11.0)$ & $498(20.6)$ & $1716(9.7)$ & $260.64^{b}$ & $<.001$ \\
\hline Chronic otitis media & $785(3.9)$ & $141(5.8)$ & $643(3.6)$ & $27.93^{\mathrm{b}}$ & $<.001$ \\
\hline Food/drug allergy & $1101(5.5)$ & $174(7.2)$ & $925(5.2)$ & $16.35^{\mathrm{b}}$ & $<.001$ \\
\hline \multicolumn{6}{|l|}{ Family history of SDB } \\
\hline Habitual snoring & $6625(32.9)$ & $1060(43.9)$ & $5558(31.4)$ & $152.43^{b}$ & $<.001$ \\
\hline OSAS & $481(2.4)$ & $93(3.9)$ & $388(2.2)$ & $25.29^{b}$ & $<.001$ \\
\hline
\end{tabular}

Family income was expressed in RMB(yuan)/person/month.

andependent-samples $t$ test.

${ }^{\mathrm{b}}$ Chi-square test.

only for age and gender, all eight factors (overweight, obesity, chronic/allergic rhinitis, asthma, otitis media, adenotonsillar hypertrophy, food/drug allergy, family history of HS and OSAS) were significantly associated with an increased likelihood of HS (Model I). After controlling simultaneously for health problems and family history, except for chronic food/drug allergy and family history of OSAS, all other six factors remained statistically significant (Model II). These associations were not found to be changed after further adjusting for 
Table 2 Associated factors regarding habitual snoring by univariate logistical regression models $(\mathbf{N}=\mathbf{2 1 , 0 5 2 )}$

\begin{tabular}{|c|c|c|c|}
\hline \multirow[t]{2}{*}{ Variables } & \multirow{2}{*}{$\begin{array}{l}\text { Prevalence of habitual snoring } \\
n(\%)\end{array}$} & \multicolumn{2}{|c|}{ Univariate regression models } \\
\hline & & OR $(95 \% \mathrm{Cl})$ & $P$ value \\
\hline \multicolumn{4}{|l|}{ Demographic characteristics } \\
\hline Age (years, mean $\pm S D$ ) & & & .040 \\
\hline $5-6$ & 309 (12.6) & $1.24(1.14-1.47)$ & .014 \\
\hline 7- & $491(13.4)$ & $1.33(1.14-1.55)$ & $<.001$ \\
\hline 8- & $462(12.4)$ & $1.22(1.04-1.42)$ & .013 \\
\hline 9- & $433(11.8)$ & $1.15(0.98-1.34)$ & .091 \\
\hline $10-$ & $408(11.2)$ & $1.09(0.93-1.27)$ & .309 \\
\hline $11-$ & $297(10.4)$ & 1.00 & \\
\hline Gender (\%) & & & $<.001$ \\
\hline Boys & $1437(14.5)$ & $1.62(1.49-1.77)$ & \\
\hline Girls & $963(9.5)$ & 1.00 & \\
\hline \multicolumn{4}{|l|}{ Socioeconomic characteristics } \\
\hline Family income (\%) & & & $<.001$ \\
\hline$<800$ & $671(13.8)$ & $1.36(1.19-1.55)$ & $<.001$ \\
\hline $800-2500$ & 1309 (11.6) & $1.11(0.99-1.25)$ & .082 \\
\hline$\geq 2500$ & 401 (10.6) & 1.00 & \\
\hline Mather's education level (\%) & & & .409 \\
\hline Low & $644(11.7)$ & $0.94(0.85-1.05)$ & .284 \\
\hline Medium & $770(11.6)$ & $0.94(0.85-1.04)$ & .237 \\
\hline High & $940(12.3)$ & 1.00 & \\
\hline Father's education level (\%) & & & .548 \\
\hline Low & $587(12.4)$ & $1.04(0.93-1.16)$ & .354 \\
\hline Medium & $802(11.7)$ & $0.98(0.88-1.08)$ & .442 \\
\hline High & $1008(12.0)$ & 1.00 & \\
\hline \multicolumn{4}{|l|}{ Chronic health problems } \\
\hline Obesity/overweight & & & $<.001$ \\
\hline Obesity & $349(16.2)$ & $1.67(1.15-1.66)$ & $<.001$ \\
\hline Overweight & $320(15.4)$ & $1.57(1.37-1.81)$ & $<.001$ \\
\hline Normal or under & $1344(10.4)$ & 1.00 & \\
\hline Chronic or allergic rhinitis & & & $<.001$ \\
\hline Yes & $421(22.4)$ & $2.35(2.09-2.65)$ & \\
\hline No & $1990(10.9)$ & 1.00 & \\
\hline Asthma & & & $<.001$ \\
\hline Yes & $138(21.7)$ & $2.10(1.73-2.55)$ & \\
\hline No & $2274(11.7)$ & 1.00 & \\
\hline Adenotonsillar hypertrophy & & & $<.001$ \\
\hline Yes & $498(22.5)$ & $2.43(2.17-2.71)$ & \\
\hline No & $1914(10.7)$ & 1.00 & \\
\hline Chronic otitis media & & & $<.001$ \\
\hline Yes & $141(18.0)$ & $1.65(1.37-1.99)$ & \\
\hline No & $2270(11.7)$ & 1.00 & \\
\hline Food/drug allergy & & & $<.001$ \\
\hline Yes & $174(15.8)$ & $1.41(1.19-1.67)$ & \\
\hline No & $2237(11.8)$ & 1.00 & \\
\hline \multicolumn{4}{|l|}{ Environmental exposures } \\
\hline Delivery & & & $<.001$ \\
\hline Caesarean sectionh & 906 (13.6) & $1.25(1.15-1.37)$ & \\
\hline Vaginal Birth & $1497(11.2)$ & 1.00 & \\
\hline \multicolumn{4}{|c|}{ Feeding patterns during the first four months } \\
\hline Breasting feeding & $1512(11.4)$ & 1.00 & .001 \\
\hline
\end{tabular}


Table 2 Associated factors regarding habitual snoring by univariate logistical regression models $(\mathrm{N}=21,052)$ (Continued)

\begin{tabular}{lcc}
\hline Mixed/bottle feeding & $896(13.1)$ & $1.16(1.07-1.27)$ \\
Breast feeding & $1230(11.2)$ & 1.00 \\
$\geq 6$ months & $1182(12.9)$ & $1.21(1.08-1.56)$ \\
$<6$ months & $76(19.5)$ & $1.81(1.41-2.33)$ \\
Pregnancy maternal smoking & $2333(11.8)$ & 1.00 \\
$\quad$ Yes & & $1.19(1.08-1.31)$ \\
$\quad$ No & $668(13.4)$ & 1.00 \\
Household passive smoking & $1735(11.5)$ & $<.001$ \\
$\quad$ Yes & & $1.72(1.57-1.87)$ \\
No & $1060(16.0)$ & 1.00 \\
Family history of SDB & $1352(10.0)$ & $<.001$ \\
Habitual snoring & & $1.79(1.42-2.26)$ \\
Yes & $93(19.3)$ & 1.00 \\
No & $2319(11.8)$ & $<.001$ \\
Yes & & $<.001$ \\
No & & \\
\hline
\end{tabular}

Family income was expressed in RMB(yuan)/person/month.

OR: odds ratio; $\mathrm{Cl}$ : confidence interval.

socioeconomic factors and environmental exposures, indicating these six factors were independent risk factors for HS in our sampled children (Model III).

The strength of association between asthma and HS varied between different age groups $(\mathrm{OR}=2.42$ for $5-6$ years, $\mathrm{OR}=1.94$ for 7 years; $\mathrm{OR}=1.45$ for 8 years; $\mathrm{OR}$ $=1.28$ for 9 years; OR not remained significant for 10 and 11 years; $\mathrm{p}$ for interaction $=.003$ ).

\section{Discussion}

Based on a large nationally representative sample, this study demonstrated that the prevalence of HS, defined as loud snoring at least two nights per week, was $12.0 \%$ in our sampled Chinese school-aged children. The factors associated with HS covered several domains: socioeconomic characteristics, environmental exposures, chronic health problems, and family history.

\section{Prevalence of HS in school-aged children}

To the best of our knowledge, this was the largest epidemiological study on childhood HS $(n=20,152)$. Due to a large sample recruited from eight cities with geographical and socioeconomic diversity and a good response rate $(92.5 \%)$, the results of this study entailed extended information for understanding childhood HS and the correlates.

The prevalence of HS in our sample was $12.0 \%$, which was slightly higher than that reported in Thai (sample aged 6 to 13 years) and Hong Kong (sample aged 6 to 12 years) districts (6.9\% and 10.9 , respectively) [20,21]. There was evidence that SDB was higher prevalent in younger children than in the older because of the higher volumetric adenoids/rhinopharynx ratio, with a peak between 2 and 8 years [28]. Compared to studies in Thai and Hong Kong districts, our studied sample was slightly younger (aged 5.08 to 12 years). In addition, the definition criteria of HS in our study was a little mild than that the two studies adopted. Taken together, the different age groups and definition of HS may explain, at least partly, the discrepancy in the prevalence of HS.

In consistent to the study in Hong Kong, our study demonstrated that boys were liable to have HS [21]. However, the gender difference was not found in the study of Thai district [20]. An interesting age differences in the prevalence of HS were found: first significantly increased from 5-6 to 7 years old and then gradually declined (12.6\%-13.4\%-10.4\%). The specific waving prevalence of HS from 5-6 to 11 years has not previously been reported and may be explained, or at least partly, by the age-dependent biological development in size of adenoid and changes in atopic diseases during childhood $[29,30]$. More studies are needed to assess the age difference, which may be valuable in exploring the biological predisposing factors regarding childhood HS.

\section{Association with socioeconomic characteristics and environmental exposures}

The present study revealed that lower fathers' educational level and lower family income were independent predisposing factors for HS. The association between SES and HS has been previously reported and the results were very similar to the findings of our study 
Table 3 Socioeconomic and environmental factors regarding habitual snoring by multivariate logistical regression models $(\mathrm{N}=\mathbf{2 1}, \mathbf{0 5 2})$

\begin{tabular}{|c|c|c|c|c|c|c|}
\hline \multirow[t]{2}{*}{ Variables } & \multicolumn{2}{|l|}{ Model I } & \multicolumn{2}{|l|}{ Model II } & \multicolumn{2}{|l|}{ Model III } \\
\hline & $\begin{array}{l}\text { Adjusted OR }(95 \% \\
\mathrm{Cl})\end{array}$ & $\begin{array}{c}P \\
\text { value }\end{array}$ & $\begin{array}{l}\text { Adjusted OR (95\% } \\
\mathrm{Cl})\end{array}$ & $\begin{array}{c}P \\
\text { value }\end{array}$ & $\begin{array}{l}\text { Adjusted OR (95\% } \\
\mathrm{Cl})\end{array}$ & $\begin{array}{c}P \\
\text { value }\end{array}$ \\
\hline \multicolumn{7}{|l|}{ Socioeconomic characteristics } \\
\hline Family income & & $<.001$ & & $<.001$ & & $<.001$ \\
\hline$<800$ vs. $\geq 2500$ & $1.35(1.18-1.54)$ & $<.001$ & $1.43(1.23-1.67)$ & $<.001$ & $1.46(1.23-1.75)$ & $<.001$ \\
\hline $800-2500$ vs. $\geq 2500$ & $1.12(0.99-1.26)$ & .072 & $1.16(1.02-1.32)$ & .024 & $1.12(0.96-1.30)$ & .142 \\
\hline \multicolumn{7}{|l|}{ Mather's education level } \\
\hline Low vs. High & NS & & NS & & NS & \\
\hline Medium vs. High & NS & & NS & & NS & \\
\hline Father's education level & & & & .007 & & $<.001$ \\
\hline Low vs. High & NS & & $1.22(1.08-1.38)$ & .002 & $1.38(1.20-1.60)$ & $<.001$ \\
\hline Medium vs. High & NS & & $1.04(0.94-1.16)$ & .427 & $1.14(1.01-1.29)$ & .034 \\
\hline \multicolumn{7}{|l|}{ Environmental exposures } \\
\hline \multicolumn{7}{|l|}{ Delivery } \\
\hline Caesarean section vs. Vaginal Birth & $1.21(1.11-1.33)$ & $<.001$ & $1.19(1.08-1.31)$ & $<.001$ & NS & \\
\hline \multicolumn{7}{|l|}{$\begin{array}{l}\text { Feeding patterns during the first four } \\
\text { months }\end{array}$} \\
\hline Mixed/bottle feeding vs. Breastfeeding & $1.16(1.06-1.27)$ & .001 & NS & & & \\
\hline \multicolumn{7}{|l|}{ Breastfeeding } \\
\hline$<6$ months vs. $\geq 6$ months & $1.19(1.09-1.29)$ & $<.001$ & $1.14(1.05-1.25)$ & .003 & $1.17(1.08-1.28)$ & $<.001$ \\
\hline \multicolumn{7}{|l|}{ Pregnancy maternal smoking } \\
\hline Yes vs. No & $1.81(1.42-2.38)$ & $<.001$ & $1.68(1.28-2.21)$ & $<.001$ & $1.51(1.07-2.13)$ & .019 \\
\hline \multicolumn{7}{|l|}{ Household passive smoking } \\
\hline Yes vs. No & $1.18(1.07-1.30)$ & .001 & $1.16(1.05-1.29)$ & .003 & NS & \\
\hline
\end{tabular}

Family income was expressed in RMB(yuan)/person/month.

OR: odds ratio; $\mathrm{Cl}$ : confidence interval.

Model I adjusted for age and gender;

Model II adjusted for age, gender, and all socioeconomic and environmental factors.

Model III adjusted for age, gender, all socioeconomic and environmental factors, and all health problems and family history simultaneously.

$[17,20,31,32]$. In addition, a recent study also found that single parent and overcrowded household could increase the risk of childhood HS [17]. Taken together, disadvantaged SES was an important predictor for childhood HS.

Previous studies showed that there was an association between childhood snoring and smoking exposure $[17,20,30,32]$. Moreover, a study in preschool children confirmed a dose-dependent effect of household smoking exposure on HS [17]. Our study demonstrated that both pregnancy maternal smoking and household passive smoking were associated with HS after adjusting for socioeconomic characteristics and environmental exposures. However, only pregnancy maternal pregnancy remained significant after further adjusting for health problems and family history and the association was stronger in girls than in boys. In fact, children with prenatal smoking exposure may currently expose to household smoking. Therefore, we could not simply exclude the effect of household smoking on childhood HS. Our results suggested that girls were more vulnerable to smoking exposure, which was a new finding and worth further research.
It was an interesting finding that breastfeeding duration was associated childhood HS. In consistent to the results of our study, a study in preschool children similarly found that longer duration of breastfeeding was a protective factor to HS, although the association did not remained significant after controlling for parental smoking [17]. However, contrary to the result of our study, a study in Singapore children aged 4-7 years suggested that breastfeeding was a risk factor to HS [30]. The contradictory results should be further interpreted or confirmed by longitudinal studies.

\section{Association with chronic health problems and family history}

In our study, a strong association was found between HS and several respiratory problems associated with atopy and infection, including chronic/allergic rhinitis, asthma, adenotonsillar hypertrophy, and otitis media, which has been previously reported $[14,15,17,18,30]$.

The mechanism underline respiratory problems and HS has not been clearly interpreted yet. A number of 
Table 4 Chronic health problems and family history regarding habitual snoring by multivariate logistical regression models $(N=21,052)$

\begin{tabular}{|c|c|c|c|c|c|c|}
\hline \multirow[t]{2}{*}{ Variables } & \multicolumn{2}{|l|}{ Model I } & \multicolumn{2}{|l|}{ Model II } & \multicolumn{2}{|l|}{ Model III } \\
\hline & Adjusted OR (95\% CI) & $P$ value & Adjusted OR (95\% Cl) & $P$ value & Adjusted OR (95\% Cl) & $P$ value \\
\hline \multicolumn{7}{|l|}{ Demographic characteristics } \\
\hline Age (years, mean $\pm S D$ ) & & .008 & & $<.001$ & & $<.001$ \\
\hline 5-6 vs. $11-$ & $1.23(1.04-1.46)$ & .015 & $1.50(1.23-1.84)$ & $<.001$ & $1.53(1.25-1.88)$ & $<.001$ \\
\hline 7- vs. 11- & $1.32(1.13-1.54)$ & $<.001$ & $1.44(1.20-1.73)$ & $<.001$ & $1.47(1.21-1.77)$ & $<.001$ \\
\hline 8- vs. $11-$ & $1.19(1.02-1.39)$ & .027 & $1.28(1.06-1.53)$ & .010 & $1.29(1.07-1.56)$ & .008 \\
\hline 9- vs. 11- & $1.15(0.98-1.34)$ & .091 & $1.16(0.96-1.40)$ & .134 & $1.18(0.97-1.44)$ & .090 \\
\hline 10- vs. 11- & $1.08(0.92-1.27)$ & .328 & $1.15(0.95-1.39)$ & .167 & $1.15(0.95-1.40)$ & .163 \\
\hline \multicolumn{7}{|l|}{ Gender } \\
\hline Boys vs. Girl & $1.62(1.48-1.76)$ & $<.001$ & $1.53(1.38-1.69)$ & $<.001$ & $1.55(1.40-1.72)$ & $<.001$ \\
\hline \multicolumn{7}{|l|}{ Chronic health problems } \\
\hline Obesity vs. normal or under & $1.54(1.35-1.78)$ & $<.001$ & $1.51(1.33-1.76)$ & $<.001$ & $1.50(1.31-1.74)$ & $<.001$ \\
\hline Overweight vs. normal or under & $1.44(1.25-1.66)$ & $<.001$ & $1.38(1.20-1.60)$ & $<.001$ & $1.35(1.16-1.56)$ & $<.001$ \\
\hline Chronic/allergic rhinitis vs. none & $2.27(2.01-2.56)$ & $<.001$ & $1.97(1.70-20.27)$ & $<.001$ & $1.94(1.66-2.25)$ & $<.001$ \\
\hline Asthma vs. none & $1.99(1.64-2.42)$ & $<.001$ & $1.46(1.14-1.87)$ & .002 & $1.43(1.11-1.84)$ & .006 \\
\hline Adenotonsillar hypertrophy vs. none & $2.35(2.10-2.63)$ & $<.001$ & $2.12(1.86-2.43)$ & $<.001$ & $2.17(1.90-2.49)$ & $<.001$ \\
\hline Chronic otitis media vs. none & $1.60(1.32-1.93)$ & $<.001$ & $1.31(1.05-1.64)$ & .017 & $1.31(1.06-1.65)$ & .021 \\
\hline Food/drug allergy vs. none & $1.38(1.16-1.64)$ & $<.001$ & NS & & NS & \\
\hline \multicolumn{7}{|l|}{ Family history of SDB } \\
\hline HS vs. none & $1.75(1.60-1.91)$ & $<.001$ & $1.67(1.51-1.85)$ & $<.001$ & $1.70(1.52-1.89)$ & $<.001$ \\
\hline OSAS vs. none & $1.81(1.43-2.28)$ & $<.001$ & NS & & NS & \\
\hline
\end{tabular}

OR: odds ratio; $\mathrm{Cl}$ : confidence interval.

Model I adjusted for age and gender;

Model II adjusted for age, gender, and all health problems and family history.

Model III adjusted for age, gender, all socioeconomic and environmental factors, and all health problems and family history simultaneously.

studies tried to explore and clarify the mechanism [29-32]. In brief, respiratory problems could increase upper airway resistance and affect airway compliance and consequently resulted to HS [33,34]. In turn, HS may exacerbate some respiratory problems such as asthma by increasing cholinergic tone and promote bronch constriction [35]. In addition, a recent study showed early exposure to respiratory syncytial virus

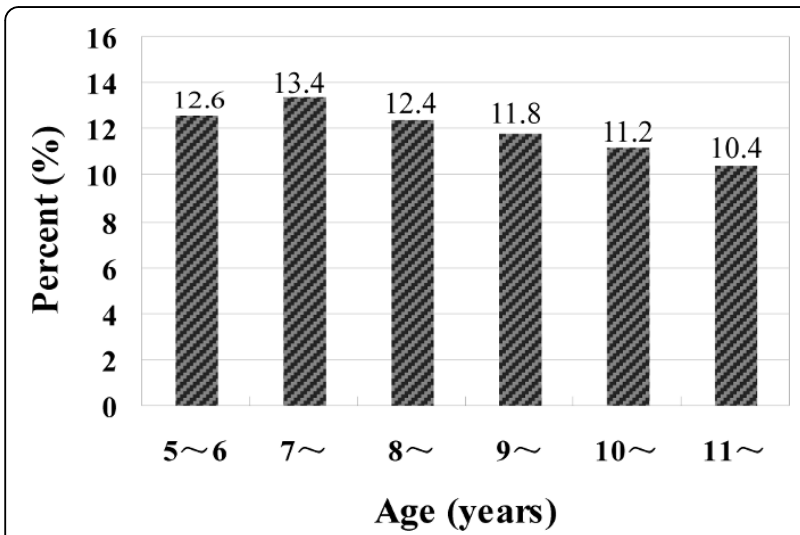

Figure 1 The prevalence of HS in Chinese school-aged children $(n=20,152)$. might induce neuro-immunomodulatory changes within adenotonsillar tissue [36]. In one word, respiratory problems and HS may be linked through some unknown intrinsic mechanisms, in which airway inflammation was irritated and neuromuscular control of breathing was disturbed.

Accumulating studies indicated that obesity was an independent predisposing factor for childhood HS $[32,33,37]$, which was in accordance to the results of this study. Moreover, our study found a dose-response relationship in that the OR values became greater as the weight status increased (OR $=1.50$ for obesity and $O R$ $=1.37$ for overweigh). In addition, there was evidence that the relationship between HS and obesity varied between different age groups and the strength was stronger in older children [32,38]. However, our study did not find this age-dependent change ( $\mathrm{p}$ for interaction >.05).

Our study also found that family history of HS was another strong risk factor for childhood HS. Therefore, it was hypothesized that HS might result from an interaction between underlying host predisposition, various intrinsic mechanisms, and external triggers. That was to say, HS was the combined outcome of environment and heredity. 


\section{Limitations}

The present study was limited by the reliance on a subjective measure, which may increase the possibility of rater biases. Fortunately, previous study has shown a high agreement between parental reports and polysomnography recording of snoring frequency [39]. In addition, although polysomnography recording was the standard method for recording of snoring frequency, it maybe not appropriate for such a large population survey. Secondly, compared to habitual snoring, researches on obstructive sleep apnea (OSA) maybe have stronger clinical significance. However, a more recent study indicated that, as the predictive symptoms for OSA, childhood HS, even without apnea, must now be paid close attention and children with HS must be considered to be an at-risk population [40]. Therefore, the present study retained updating clinical significance. Thirdly, although our study included a large number of possible risk factors of HS, the analysis may have been imperfect and noncomprehensive. For example, a more recent study reported that traffic exposure was a risk factor to childhood HS [17]. Due to the fact that we did to collect information on traffic exposure during the survey, it was impossible to assess the relationship between traffic exposure and HS in our sampled children. Moreover, some unknown factors related to HS may responsible for part of the associations reported herein. Finally, since there was evidence that SDB was higher prevalent in younger children than in the older because of the higher volumetric adenoids/rhinopharynx ratio [28], the findings of our study could not be extended to younger children.

\section{Conclusions}

This study provided information on the prevalence of HS and associated risk factors in Chinese school-aged children. Our findings suggested that HS was common in school-aged children and associated factors covered socioeconomic status, environmental factors, and biological susceptibility. Upon the recognition that HS has potential severe complications due to increased sleep fragmentation, theses findings, although should be further confirmed by prospective studies, had important clinical implication for formulating intervention and treatment schemes.

\footnotetext{
Abbreviations

HS: habitual snoring; SDB: sleep-disordered breathing; CSHQ: the Children's Sleep Habits Questionnaire; SES: socioeconomic status; BMI: body mass index; SE: standard error; OR: odds ratio; Cl: confidence interval.

Disclosure Statement

All authors indicate no potential conflicts of interests.

\section{Authors' contributions}

SL participated in the design, analysis, interpretation and drafted the manuscript. XS participated in the design and coordination of the study, acquisition of data and to critically draft the manuscript. XJ, CY, SW and FJ
}

participated in the design, acquisition of data and to critically draft the manuscript. All authors read and approved the final manuscript.

\section{Acknowledgements}

The study was supported by grants from the Shanghai Key Laboratory of Children's Environmental Health (06DZ22024), National Natural Science Foundation of China (30700670, 81072314), Innovation Program of Shanghai Municipal Education Commission (Grant 09YZ92); Program for Excellent Young Teachers in Shanghai (Grant jdy-07011); 2008 Chenxin Award Project for Young Scholar in Shanghai Jiaotong University; and 2009 New Bairenjihua in Shanghai Jiaotong University School of Medicine.

\section{Author details}

${ }^{1}$ From the Shanghai Xin Hua Hospital affiliated with Shanghai Jiaotong University School of Medicine, Shanghai, People's Republic of China. ${ }^{2}$ School of Public Health affiliated with Shanghai Jiaotong University School of Medicine, Shanghai, People's Republic of China. ${ }^{3}$ Shanghai Children's Medical Center affiliated with Shanghai Jiaotong University School of Medicine, Shanghai, People's Republic of China. "Shanghai Key Laboratory of Children's Environmental Health, Shanghai, People's Republic of China.

Received: 7 January 2010 Accepted: 19 October 2010 Published: 19 October 2010

\section{References}

1. Brunetti L, Rana S, Lospalluti ML, Pietrafesa A, Francavilla R, Fanelli M, Armenio L: Prevalence of obstructive sleep apnea syndrome in a cohort of 1,207 children of southern Italy. Chest 2001, 120:1930-1935.

2. Petry C, Pereira MU, Pitrez PM, Jones MH, Stein RT: The prevalence of symptoms of sleep-disordered breathing in Brazilian schoolchildren. $J$ Pediatr 2008, 84:123-129.

3. Schlaud M, Urschitz MS, Urschitz-Duprat PM, Poets CF: The German study on sleep-disordered breathing in primary school children: epidemiological approach, representativeness of study sample, and preliminary screening results. Paediatr Perinat Epidemio/ 2004, 18 431-440

4. Zhang G, Spickett J, Rumchev K, Lee AH, Stick S: Snoring in primary school children and domestic environment: a Perth school based study. Respir Res 2004, 5:19.

5. Tauman $R, O$ 'Brien LM, Holbrook CR, Gozal D: Sleep pressure score: a new index of sleep disruption in snoring children. Sleep 2004, 27:274-278.

6. Gozal D, Capdevila OS, Kheirandish-Gozal L: Metabolic alterations and systemic inflammation in obstructive sleep apnea among nonobese and obese prepubertal children. Am J Respir Crit Care Med 2008, 177:1142-1149.

7. Archbold KH, Pituch KJ, Panahi P, Chervin RD: Symptoms of sleep disturbances among children at two general pediatric clinics. J Pediatr 2002, 140:97-102.

8. Sahin U, Ozturk O, Ozturk M, Songur N, Bircan A, Akkaya A: Habitual snoring in primary school children: prevalence and association with sleep-related disorders and school performance. Med Princ Pract 2009, 18:458-465.

9. Gozal D, Sans Capdevila O, McLaughlin Crabtree V, Serpero LD, Witcher LA, Kheirandish-Gozal L: Plasma IGF-1 levels and cognitive dysfunction in children with obstructive sleep apnea. Sleep Med 2009, 10:167-173.

10. Aronen ET, Liukkonen K, Simola P, Virkkula P, Uschakoff A, Korkman M, Kirjavainen T, Pitkäranta A: Mood is associated with snoring in preschoolaged children. J Dev Behav Pediatr 2009, 30:107-114.

11. Kheirandish L, Gozal D: Neurocognitive dysfunction in children with sleep disorders. Dev Sci 2006, 9:388-399.

12. Amin RS, Carroll JL, Jeffries JL, Grone C, Bean JA, Chini B, Bokulic R, Daniels SR: Twenty-four hour ambulatory blood pressure in children with sleep-disordered breathing. Am J Respir Crit Care Med 2004, 169:950-956.

13. Kwok KL, Ng DK, Chan $\mathrm{CH}$ : Cardiovascular changes in children with snoring and obstructive sleep apnoea. Ann Acad Med Singapore 2008, 37:715-721.

14. Dayyat E, Kheirandish-Gozal L, Sans Capdevila O, Maarafeya MM, Gozal D: Obstructive sleep apnea in children: relative contributions of body mass index and adenotonsillar hypertrophy. Chest 2009, 136:137-144. 
15. Gozal D, Kheirandish-Gozal L, Sans Capdevila O, Dayyat E, Kheirandish E: Prevalence of recurrent otitis media in habitually snoring school-aged children. Sleep Med 2008, 9:549-554.

16. Montgomery-Downs HE, Gozal D: Snore-associated sleep fragmentation in infancy: mental development effects and contribution of secondhand cigarette smoke exposure. Pediatrics 2006, 117:e496-502.

17. Kuehni CE, Strippoli MP, Chauliac ES, Silverman M: Snoring in preschool children: prevalence, severity and risk factors. Eur Respir J 2008, 31:326-333.

18. Arens R, Marcus CL: Pathophysiology of upper airway obstruction: a developmental perspective. Sleep 2004, 27:997-1019.

19. Kawashima S, Niikuni N, Chia-Hung L, Takahashi Y, Kohno M, Nakajima I, Akasaka M, Sakata H, Akashi S: Cephalometric comparisons of craniofacial and upper airway structure in young children with obstructive sleep apnea syndrome. Ear Nose Throat J 2000, 79:499-502, 505-506.

20. Anuntaseree W, Kuasirikul S, Suntornlohanakul S: Natural history of snoring and obstructive sleep apnea in Thai school-age children. Pediatr Pulmonol 2005, 39:415-420.

21. Ng DK, Kwok KL, Cheung JM, Leung SY, Chow PY, Wong WH, Chan CH, Ho JC: Prevalence of sleep problems in Hong Kong primary school children: a community-based telephone survey. Chest 2005, 128:1315-1323.

22. Wysocki J, Kielska E, Orszulak P, Reymond J: Measurements of pre- and postpubertal human larynx: a cadaver study. Surg Radiol Anat 2008, 30:191-199.

23. Nelson S, Cakirer B, Lai YY: Longitudinal changes in craniofacial factors among snoring and nonsnoring Bolton-Brush study participants. Am J Orthod Dentofacial Orthop 2003, 123:338-344.

24. Chung KF, Cheung MM: Sleep-wake patterns and sleep disturbance among Hong Kong Chinese adolescents. Sleep 2008, 31:185-194.

25. Ji CY, Working Group on Obesity in China: Report on childhood obesity in China (1)-body mass index reference for screening overweight and obesity in Chinese school-age children. Biomed Environ Sci 2005, 18:390-400.

26. Owens JA, Spirito A, McGuinn M: The Children's Sleep Habits Questionnaire (CSHQ): psychometric properties of a survey instrument for school-aged children. Sleep 2000, 23:1043-1051.

27. Li SH, Jin XM, Shen XM, Wu SH, Jiang F, Yan CH, Yu XD, Qiu YL: Development and psychometric properties of the Chinese version of Children's Sleep Habits Questionnaire. Zhonghua Er Ke Za Zhi 2007, 45:176-180.

28. Lumeng JC, Chervin RD: Epidemiology of pediatric obstructive sleep apnea. Proc Am Thor Soc 2008, 5:242-252.

29. Vogler RC, li FJ, Pilgram TK: Age-specific size of the normal adenoid pad on magnetic resonance imaging. Clin Otolaryngol 2000, 25:392-395.

30. Chng SY, Goh DY, Wang XS, Tan TN, Ong NB: Snoring and atopic disease: a strong association. Pediatr Pulmonol 2004, 38:210-216.

31. Urschitz MS, Guenther A, Eggebrecht E, Wolff J, Urschitz-Duprat PM, Schlaud M, Poets CF: Snoring, intermittent hypoxia and academic performance in primary school children. Am J Respir Crit Care Med 2003, 168:464-468

32. Corbo GM, Forastiere F, Agabiti N, Pistelli R, Dell'Orco V, Perucci CA, Valente S: Snoring in 9- to 15-year-old children: risk factors and clinical relevance. Paediatrics 2001, 108:1149-1154.

33. Urschitz MS, Guenther A, Eitner S, Urschitz-Duprat PM, Schlaud M, Ipsiroglu OS, Poets CF: Risk Factor and Natural History of Habitual Snoring. Chest 2004, 126:790-800.

34. Basner RC, Simon PM, Schwartzstein RM, Weinberger SE, Weiss JW: Breathing route influences upper airway muscle activity in awake normal adults. J Appl Physiol 1989, 66:1766-1771.

35. Zettergreen-Wijk L, Linder-Aronson S, Norlander B, Agren K, Svanborg E: Longitudinal effect on facial growth after tonsillectomy in children with obstructive sleep apnea. World J Orthod 2002, 3:67-72.

36. Goldbart AD, Mager E, Veling MC, Goldman JL, Kheirandish-Gozal L, Serpero LD, Piedimonte G, Gozal D: Neurotrophins and tonsillar hypertrophy in children with obstructive sleep apnoea. Pediatr Res 2007, 62:489-494.

37. Ng DK, Lam YY, Kwok KL, Chow PY: Obstructive sleep apnea syndrome and obesity in children. Hong Kong Med J 2004, 10:44-48.

38. Kaditis AG, Alexopoulos El, Hatzi F, Karadonta I, Chaidas K, Gourgoulianis K, Zintzaras $E$, Syrogiannopoulos GA: Adiposity in relation to age as predictor of severity of sleep apnoea in children with snoring. Sleep Breath 2008, 12:25-31.

39. Montgomery-Downs HE, O'Brien LM, Holbrook CR, Gozal D: Snoring and sleep-disordered breathing in young children: subjective and objective correlates. Sleep 2004, 27:87-94.

40. Li AM, Chun TA, Crover H, Fok TK, Wing YK: Blood pressure is increased in children with primary snoring. J Pediatr 2009, 155:362-368.

doi:10.1186/1465-9921-11-144

Cite this article as: Li et al:: Habitual Snoring in school-aged children: environmental and biological predictors. Respiratory Research 2010 $11: 144$

\section{Submit your next manuscript to BioMed Central and take full advantage of:}

- Convenient online submission

- Thorough peer review

- No space constraints or color figure charges

- Immediate publication on acceptance

- Inclusion in PubMed, CAS, Scopus and Google Scholar

- Research which is freely available for redistribution
C Biomed Central 